\title{
Relationship between Tibia Length Measurements and Standing Height: A Prospective Regional Study among Adolescents in Southern Region of Kosovo
}

\author{
Jovan Gardasevic', Bojan Masanovic ${ }^{1}$ and Fitim Arifi ${ }^{2}$ \\ 'University of Montenegro, Faculty for Sport and Physical Education, Niksic, Montenegro, ${ }^{2}$ AAB College, Faculty of Physical Education and Sport, \\ Pristina, Kosovo
}

\section{Abstract}

The purpose of this research is to examine standing height in both Kosovan genders in the Southern Region as well as its association with tibia length, as an alternative to estimating standing height. A total of 225 individuals (120 male and 105 female) participated in this research. The anthropometric measurements were taken according to the protocol of ISAK. The relationships between body height and tibia length were determined using simple correlation coefficients at a ninety-five percent confidence interval. A comparison of means of standing height and tibia length between genders was performed using a t-test. After that a linear regression analysis were carried out to examine extent to which tibia length can reliably predict standing height. Results displayed that Southern Kosovan male are $178.60 \pm 5.73 \mathrm{~cm}$ tall and have a tibia length of $39.93 \pm 2.34 \mathrm{~cm}$, while Southern Kosovan female are $165.33 \pm 4.45 \mathrm{~cm}$ tall and have a tibia length of $35.50 \pm 2.07 \mathrm{~cm}$. The results have shown that both genders made Southern-Kosovans a tall group, but shorter than general Kosovan population. Moreover, the tibia length reliably predicts standing height in both genders; but, not reliably enough as arm span. This study also confirms the necessity for developing separate height models for each region in Kosovo as the results from Southern-Kosovans don't correspond to the general values.
\end{abstract}

Key words: prediction, measurement, stature, tibia length, kosovan

\section{Introduction}

According to Komunat e Kosovës (2013), Kosovo is a democratic, multi-ethnic and secular republic which administratively is subdivided into seven districts (Ferizaj, Gjakova, Gjilan, Mitrovica, Peja, Pristina and Prizren) and five regions (Eastern, Western, Northern, Southern and Central). This study analyzes the standing height and its estimation utilizing tibia length measurements in adolescents in southern region which contains five municipalities (Dragas, Malisheva, Mamusha, Prizren and Suva Reka/Suharekë). This region
(Figure 1) covers the area of 1,397 square kilometers and has population of 331,670 inhabitants, while average density per square kilometer is 240 inhabitants (Komunat e Kosovës, 2013). Although Kosovo doesn't have too big territory, it has a very varied relief that mostly belongs to Dinarides range and the author assumed this fact might influence the main objective of this study, because of the type of the soil as well as other socio-economical and geographical characteristics as a potential influencing factors (Arifi, 2017; Arifi, Sermaxhaj, Zejnullahu-Raçi, Alaj, \& Metaj, 2017b).

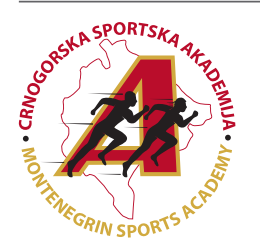

Correspondence: 


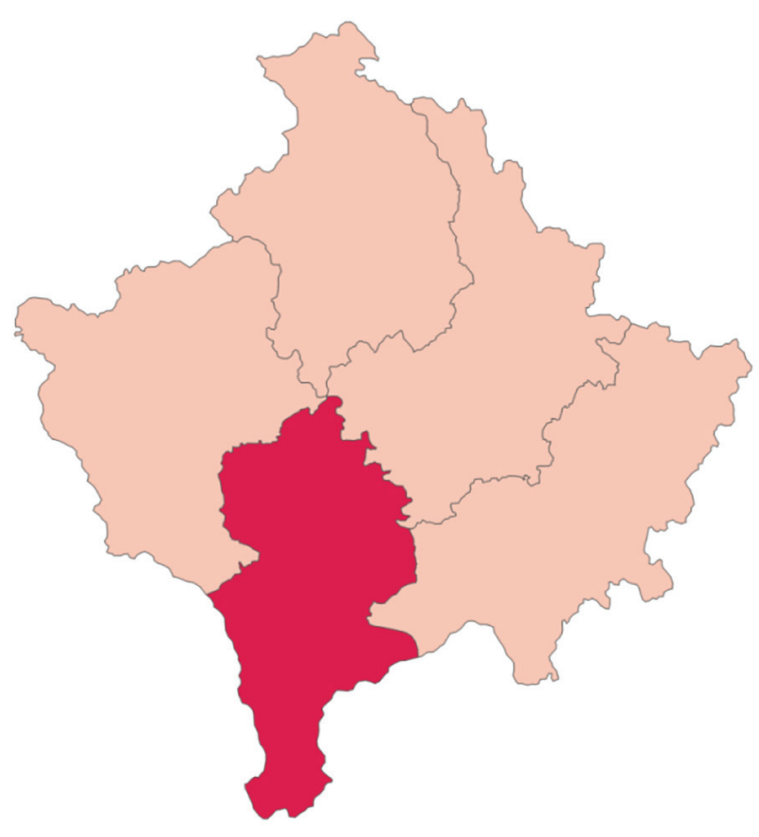

Figure 1. Geographical Location of Southern Region in Kosovo

There are lots of scientific findings which confirms that the measurement of standing height is a vitally important variable when assessing nutritional status (cited in Arifi et al., 2017a; Datta Banik, 2011; Popovic, \& Bjelica, 2016), as well as when assessing the growth of children, evaluating the basic energy requirements, adjusting the measures of physical capacity and predicting the drug dosage and setting standards of physiological variables such as muscle strength, metabolic rate, lung volumes and glomerular filtration (Golshan, Amra, \& Hoghogi, 2003; M. Golshan, Crapo, Amra, Jensen, \& R. Golshan, 2007; Mohanty, Babu, \& Nair, 2001; Ter Goon, Toriola, Musa, \& Akusu, 2011). However, according to Quanjer and his collaborators (2014), the exact standing height cannot always be identified and resolved in the usual way (e.g. paralysis, fractures, amputation, scoliosis and pain). Because of these factors, an estimate of standing height has to be acquired from other reliable anthropometric indicators such as hand and tibia lengths, foot lengths, knee height, length of the forearm, length of the sternum, vertebral column length, sitting height, length of scapula, arm span as well as cranial sutures, skull, facial measurements et cetera (cited in Gardasevic, Rasidagic, Krivokapic, Corluka, \& Bjelica, 2017; Popovic, 2017; Popovic, Gardasevic, Masanovic, Arifi, \& Bjelica, 2017; Masanovic, Gardasevic, \& Arifi, 2018a; Masanovic, Gardasevic, \& Arifi, 2018b). Therefore, all these anthropometric indicators, which are used as an alternative to estimate standing height, are very important in predicting loss in standing height connected with aging. Also, to diagnose individuals with disproportionate growth abnormalities and skeletal dysplasia or standing height loss during surgical procedures on the spine (Mohanty et al., 2001), as well as to anticipate standing height in many older people as it is very difficult to measure it precisely, and sometimes impossible because of mobility problems and kyphosis (Hickson \& Frost, 2003). Lastly, it is important to state that this knowledge finds its importance in sport science the standing height represents a significant factor which influences the success in various sport disciplines (Popovic, 2017).

Several researches have reported the benefit of using various body parameters in predicting standing height, and arm span happened to be one of the most reliable ones in adults (Hickson
\& Frost, 2003; Jalzem \& Gledhill, 1993; Mohanty et al., 2001; Ter Goon et al., 2011), while some authors (Singh, Kumar, Chavali, \& Harish, 2012) believe that foot length measurement is the most reliable predictor during adolescent age, due to the fact that ossification and maturation occurs earlier in the foot than the long bones and standing height could be more accurately predicted from foot measurement as compared to long bones during adolescent age. In addition, the relationship of long bones and standing height was found to vary in different ethnic and racial groups (Bjelica, Popovic, Kezunovic, Petkovic, Jurak, \& Grasgruber, 2012; Brown, Feng, \& Knapp, 2002; Popovic, Bjelica, Georgiev, Krivokapic, \& Milasinovic, 2016; Popovic, Bjelica, Molnar, Jaksic, \& Akpinar, 2013; Popovic, Bjelica, Tanase, \& Milasinovic, 2015; Reeves, Varakamin, \& Henry, 1996; Steele \& Chenier, 1990) as well as various regions (Arifi, 2017; Arifi et al., 2017b; Milasinovic, Popovic, Matic, Gardasevic, \& Bjelica, 2016; Milasinovic, Popovic, Jaksic, Vasiljevic, \& Bjelica, 2016; Masanovic, Gardasevic, \& Arifi, 2018c; Masanovic, Gardasevic, \& Arifi, 2018d). Hence, researchers have derived a specific formula for calculating standing height from long bones for each ethnic/race group. The mentioned variations might be the case with tibia length predictions too, mostly due to the fact that the Dinaric Alps population has specific body composition than national as well as regional point of view (Popovic, 2017). Even though many studies with this essence are available on neighboring countries as well as worldwide population, only narrow data is available on Kosovan subjects, just one conducted by Popovic, Arifi and Bjelica (2017), and Popovic and Bjelica (2017) that has covered whole Kosovan population, and one regional analyses that confirmed Western-Kosovans have specific standing height/foot length ratio, comparing to general population in Kosovo (Popovic et al., 2017). Considering rather sparse recent scientific literature, the purpose of this research was to examine the standing height in both Eastern-Kosovan genders and its association with tibia length.

\section{Methods}

The nature of this research gave extension to the 225 highschool students last year (120 male and 105 female) from Southern Region of Kosovo to be subjects. Two reasons which qualified the selected individuals are: the first is related to the fact that the growth of an individual ceases by this age, while the second is related to the fact that there is no age-related loss in standing height at this age. The average age of the male subject was $18.40 \pm 0.56$ years old (range 18-20 years), while the average age of the female subject was $18.36 \pm 0.50$ years old (range $18-20$ years). It is important to underline that the researchers have excluded from the data analysis of the individuals with physical deformities as well as those without informed consent. The exclusion criterion was also being non-Southern Kosovan.

The anthropometric measurements, including standing height and tibia length, were taken according to the protocol of the International Society for the Advancement of Kinanthropometry (Marfell-Jones, Olds, Stew, \& Carter, 2006). The trained measurers have measured selected anthropometric indicators (same measurer for each indicator), while the quality of their performance was evaluated against the prescribed "ISAK Manual". Lastly, the age of the each subject was reached directly from the birthdays.

The analysis were performed by using the Statistical Package for Social Sciences (SPSS) version 20.0. Means and standard deviations (SD) were obtained for both anthropometric variables. A comparison of means of standing height and tibia length between genders was performed using a t-test. The relationships between 
standing height and tibia length were determined using simple correlation coefficients at ninety-five percent confidence inter$\mathrm{val}$. Then a linear regression analysis were carried out to examine the extent to which the tibia length can reliably predict standing height. Statistical significance was set at $\mathrm{p}<0.05$.

\section{Results}

A summary of the anthropometric measurements in both genders is shown in Table 1 . The mean of the standing height for male was $178.60 \pm 5.73$ centimeters and tibia length was $39.93 \pm 2.34$ centimeters, while for female the standing height was $165.33 \pm 4.45$ centimeters and tibia length was $35.50 \pm 2.07$ centimeters. The sex difference between standing height and tibia length measurements was statistically significant (standing height: $\mathrm{t}=19.183 ; \mathrm{p}<.000$. and tibia length: $\mathrm{t}=14.927 ; \mathrm{p}<.000)$.

Table 1. Anthropometric Measurements of the Study Subjects

\begin{tabular}{ccc}
\hline Subjects & $\begin{array}{c}\text { Standing Height Range } \\
\text { (Mean } \pm \text { SD) }\end{array}$ & $\begin{array}{c}\text { Tibia Length Range } \\
\text { (Mean } \pm \text { SD) }\end{array}$ \\
\hline \multirow{2}{*}{ Male } & $164.6-192.3$ & $33.1-47.7$ \\
& $(178.60 \pm 5.73)$ & $(39.93 \pm 2.34)$ \\
Female & $158.0-184.0$ & $30.7-40.7$ \\
& $(165.33 \pm 4.45)$ & $(35.50 \pm 2.07)$ \\
\hline
\end{tabular}

In Table 2, the simple correlation coefficients and their ninety-five percent confidence interval analysis between the anthropometric measurements are displayed. The associations between standing height and tibia length were significant $(\mathrm{p}<0.000)$ and high in this sample, regardless of gender (male: 0.734; female: 0.639).

Table 2. Correlation between Standing Height and Tibia Length of the Study Subjects

\begin{tabular}{|c|c|c|c|}
\hline Subjects & $\begin{array}{l}\text { Correlation } \\
\text { Coefficient }\end{array}$ & $\begin{array}{l}\text { 95\% confidence } \\
\text { interval }\end{array}$ & $\begin{array}{l}\text { Significance } \\
\text { p-value }\end{array}$ \\
\hline Male & 0.734 & $0.610-0.858$ & $<0.000$ \\
\hline Female & 0.639 & $0.489-0.789$ & $<0.000$ \\
\hline
\end{tabular}

The results of the linear regression analysis are shown in Table 3. The first of all models were extracted by including age as a covariate. However, it was found that the contribution of age was insignificant and therefore the age was dropped and estimations were derived as a univariate analysis. The high val- ues of the regression coefficient (male: 0.734 ; female: 0.639 ) signify that tibia length notably predicts standing height in both Southern-Kosovan genders (male: $t=11.740$, $p<0.000$; female: $\mathrm{t}=8.432, \mathrm{p}<0.000$ ), which confirms the R-square (\%) for the male (53.9) as well as for the female (40.8).

Table 3. Results of Linear Regression Analysis Where the Tibia Length Predicts the Standing Height

\begin{tabular}{cccccc}
\hline Subjects & $\begin{array}{c}\text { Regression } \\
\text { Coefficient }\end{array}$ & $\begin{array}{c}\text { Standard } \\
\text { Error (SE) }\end{array}$ & $\begin{array}{c}\text { R-square } \\
\text { (\%) }\end{array}$ & t-value & p-value \\
\hline Male & 0.734 & 3.911 & 53.9 & 11.740 & 0.000 \\
Female & 0.639 & 3.443 & 40.8 & 8.432 & 0.000 \\
\hline
\end{tabular}

The associations between tibia length measurements and standing height among the above models is sketched as a scat-

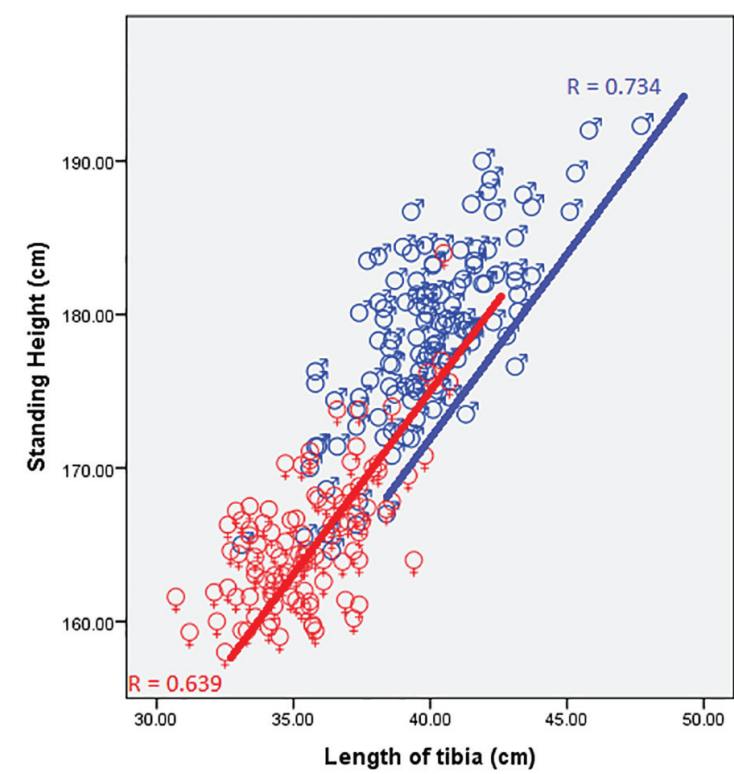

ter diagrams (Figure 2).
O'Male $^{7}$ O Female
Or

Figure 2. Scatter Diagram and Relationship between Tibia Length Measurements and Standing Height among Both Genders 


\section{Discussion}

The assessment of standing height using various anthropometric measures is very typical from the past centuries and it has been attempted to be studied by many researchers. However, it is important to underline that the arm span has been obtained as the most reliable body indicator for predicting the standing height of an individual (Mohanty et al., 2001; Ter Goon et al., 2011), while tibia length is was very close (Khatun, Sharma, Jain, \& Gupta, 2016; A. Kaore, B.P. Kaore, Kamdi, S. Kaore, 2012; Agnihotri, Smita, Jowaheer, \& Pratap, 2009). In parallel, it is important to emphasize that the individual and ethnic variations referring to standing height and its association with tibia length might vary from ethnic group to ethnic group as well as race to race, because the racial and ethnic differences are affective on these measures and reduce the possibility of generalizing (cited in Bjelica et al., 2012). This fact confirms the study conducted by authors (Agnihotri et al., 2009) who confirmed a very high linear correlation between standing height and tibia length in both genders, while the research study conducted by Khatun and her collaborators (2016) shows significant correlation between standing height and tibia length in both genders of Indian population. The highest correlation coefficient in this population was found for tibia length in males $(r=0.67)$ as well as in females $(r=0.58)$.

All above-mentioned have confirmed the necessity for developing separate standing height models for each population on account of ethnic differences and the recent study conducted by Popovic and his collaborators (Popovic et al., 2017a; Popovic \& Bjelica, 2017) who have analyzed the entire Kosovan population and have found specific correlation coefficient standing height and foot length in Kosovan male $(\mathrm{r}=0.669)$ and female $(\mathrm{r}=0.625)$ population; however, some recent studies have also confirmed the regional differences between the same ethnic groups too (Arifi, 2017; Arifi et al., 2017b; Popovic et al., 2017b; Milasinovic et al., 2016a; 2016b), which caused the need for additional caution, mostly due to the reason one of them was sampled by Western-Kosovans. Therefore, the main goal of this research was to test the hypothesis if above-mentioned facts are true for the SouthernKosovans, that is, for the one of five Kosovan regions. As the correlation between tibia length and standing height was significant in both Southern-Kosovan genders, the tibia length measure therefore seems to be a reliable indirect anthropometric indicator for estimating standing height in both genders of Southern-Kosovan population.

The results of the study conducted by Popovic and his collaborators (Popovic et al., 2017a; Popovic \& Bjelica, 2017; Masanovic, 2017) confirm the necessity for developing separate standing height models for both genders in Kosovo but the authors of the same study have recommended that further studies should consider dividing the population of this country to regional subsamples and analyze it separately, just to be sure there are no geographical differences (such as type of the soil) influencing the average standing height in both Kosovan genders as well as its association with tibia length. This concern was based on the fact that entire Kosovo doesn't fall into Dinaric Alps racial classification. In parallel, this study confirms the assumption mentioned above and also confirms that it is necessary to develop separate standing height models for each population on account of regional variations in Kosovo.

Next to highlighted issue, the obvious constraint of this research might also be the composition of the measured sample that consisted of high school students. This limitation is based on the fact there are some studies which assumed the growth of an individual doesn't cease by this age (Grasgruber, P., personal communication, 2016; Jurak, G., personal communication, 2017). This assumption might be supported by the fact that university-educated individuals have been founded to be taller than the high school population in Bosnia and Herzegovina (Grasgruber et al., 2017; Gardasevic et al., 2017), Poland (Wronka \& Pawlinska-Chmara, 2009) and Hungary (Szollosi, 1998). On the other hand, this wasn't the truth in Montenegro (Popovic, 2016) and comparing the average standing height measures of this study to the results of some study sampled by university students might give the science much precise conclusions. One more obvious limitation of this study is also the fact that both genders of Kosovo did not reach their full genetic potential yet, since various environmental factors controlled their development. Further continuous monitoring is necessary, mostly due to the reason it is expected the secular changes influencing standing height will ascend in the following two or three decades.

\section{Acknowledgements}

There are no acknowledgements.

\section{Conflict of Interest}

The authors declare that there are no conflicts of interest.

Received: 28 May 2018 | Accepted: 09 July 2018 | Published: 01 October 2018

\section{References}

Agnihotri, A.K., Smita, K., Jowaheer, V., Pratap, A. (2009). Estimation of stature from percutaneous length of tibia and ulna in Indo-Mauritian population. Forensic Science International, 187, 109-113.

Arifi, F. (2017). Stature and its estimation utilizing arm span measurements of both gender adolescents from southern region in Kosovo. Sport Science, 10(1), 92-95.

Arifi, F., Bjelica, D., Sermaxhaj, S., Gardasevic, J., Kezunovic, M., \& Popovic, S. (2017a). Stature and its Estimation Utilizing Arm Span Measurements in Kosovan Adults: National Survey. International Journal of Morphology, 35(3), 1161-1167.

Arifi, F., Sermaxhaj, S., Zejnullahu-Raçi, P., Alaj, I., \& Metaj, Z. (2017b). Stature and its estimation utilizing arm span measurements of both gender adolescents from northern region in Kosovo. Acta Kinesiologica, 11(1), 49-52.

Bjelica, D., Popovic, S., Kezunovic, M., Petkovic, J., Jurak, G., \& Grasgruber, P. (2012). Body Height and Its Estimation Utilizing Arm Span Measurements in Montenegrin Adults. Anthropological Notebooks, 18(2), 69-83.

Brown, J.K., Feng, J.Y., \& Knapp, T.R. (2002). Is self-reported height or arm span a more accurate alternative measure of height? Clinical Nursing Research, 11(4), 417-432.

Datta Banik, S. (2011). Arm span as a proxy measure for height and estimation of nutritional status: A study among Dhimals of Darjeeling in West Bengal India. Annals of Human Biology, 38(6), 728-735.

Gardasevic, J., Rasidagic, F., Krivokapic, D., Corluka, M., \& Bjelica, D. (2017). Stature and Its Estimation Utilizing Arm Span Measurements in Male Adolescents from Federation of Bosnia and Herzegovina Entity in Bosnia and Herzegovina. Montenegrin Journal of Sports Science and Medicine, 6(1), 37-44.

Golshan, M., Amra, B., \& Hoghogi, M.A. (2003). Is arm span an accurate measure of height to predict pulmonary function parameters? Monaldi Archives for Chest Disease, 59(3), 189-192.

Golshan, M., Crapo, R.O., Amra, B., Jensen, R.I., \& Golshan, R. (2007). Arm span as an independent predictor of pulmonary function parameters: validation and reference values. Respirology, 12(3), 361-366.

Grasgruber, P., Popovic, S., Bokuvka, D., Davidovic, I., Hřebíckova, S., Ingrova, P., Potpara, P., Prce, S., \& Stracarova, N. (2017). The mountains of giants: an anthropometric survey of male youths in Bosnia and Herzegovina. Royal Society Open Science, 4, 161054.

Hickson, M. \& Frost, G.A (2003). Comparison of three methods for estimating height in the acutely ill elderly population. Journal of Human Nutrition and Dietitian, 16(1), 13-20. 
Jalzem, P.F. \& Gledhill, R.B. (1993). Predicting height from arm span measurements. Journal of Pediatric Orthopedics, 13(6), 761-765.

Kaore, A., Kaore, B.P., Kamdi, A., Kaore, S. (2012). Stature estimation from tibial length. NJIRM, 3(2), 51-6.

Khatun, S.S., Sharma, N., Jain, S.K., \& Gupta, A. (2016). Estimation of stature from percutaneous tibial length in Indian population. Int $J$ Anat Res, 4(3):2571-2576. doi: 10.16965/ijar.2016.278

Komunat e Kosovës (2013). Pristina: Gjiganti. Retrieved on March 25, 2017 from http://www.gjiganti.com/kosova/komunat/.

Marfell-Jones, M., Olds, T., Stew, A.D., \& Carter, J.E.L. (2006). International standards for anthropometric assessment. Potchesfstroom: International Society for the Advancement of Kinanthropometry.

Masanovic, B. (2017). Relationship between arm span measurements and body height in Dinaric Alpes population: A systematic review. Journa of Anthropology of Sport and Physical Education, 1(1), 33-37.

Masanovic, B., Gardasevic, J., \& Arifi, F. (2018a). Relationship between foot length measurements and body height: A prospective regional study among adolescents in eastern region of Kosovo. Sport Mont, 16(1), 9-13. doi: $10.26773 /$ smj.180202

Masanovic, B., Gardasevic, J., \& Arifi, F. (2018b). Relationship between Foot Length Measurements and Body Height: A Prospective Regional Study among Adolescents in Northern Region of Kosovo. AnthropologieInternational Journal of Human Diversity and Evolution, in pres, https:// doi.org/10.26720/anthro.18.01.23.1

Masanovic, B., Gardasevic, J., \& Arifi, F. (2018c). Relationship between foot length measurements and standing height: a prospective regional study among adolescents in southern region of kosovo. Sport Mont, 16(2), 27-31. doi: 10.26773/smj.180605

Milasinovic, R., Popovic, S., Matic, R., Gardasevic, J., \& Bjelica, D. (2016a). Body Height and its Estimation Utilizing Arm Span Measurements in Male Adolescents from Southern Region in Montenegro. Sport Mont, 14(2), 21-23.

Milasinovic, R., Popovic, S., Jaksic, D., Vasiljevic, I., \& Bjelica, D. (2016b) Stature and its Estimation Utilizing Arm Span Measurements in Feale Adolescents from Southern Region in Montenegro. Sport Mont, 14(3), $15-18$.

Mohanty, S.P., Babu, S.S., \& Nair, N.S. (2001). The use of arm span as a predictor of height. A study of South Indian women. Journal of Orthopedics Surgery, 9(1), 19-23.

Popovic, S. (2016). Body Height and its Estimation Utilizing Arm Span Measurements in Montenegrin Adults: National Survey. In Book of Summaries of 11th FIEP European Congress "Anthropological Aspects of Sport, Physical Education and Recreation" (5-6), Banjaluka: University of Banjaluka, Faculty of Physical Education and Sport.

Popovic, S. (2017). Local Geographical Differences in Adult Body Height in Montenegro. Montenegrin Journal of Sports Science and Medicine, 6(1), 81-87.

Popovic, S., Arifi, F., \& Bjelica, D. (2017). Standing Height and its Estimation Utilizing Foot Length Measurements in Kosovan Adults: National
Survey. International Journal of Applied Exercise Physiology, 6(2), 1-7.

Popovic, S., Gardasevic, J., Masanovic, B., Arifi, F. \& Bjelica, D. (2017). Standing Height and its Estimation Utilizing Foot Length Measurements in Adolescents from Western Region in Kosovo. Sport Mont, 15(3), 3-7. doi: 10.26773/smj.2017.10.001

Popovic, S. \& Bjelica, D. (2016). Body Height and its Estimation Utilizing Arm Span Measurements in Kosovan Adolescence: National Survey. In Abstract Book of International Eurasian Conference on Sport, Education, and Society (9), Antalya: International Science Culture and Sport Association.

Popovic, S., \& Bjelica, D. (2017). Body Height and its Estimation Utilizing Foot Length Measurements in Kosovan Adults: National Survey, In Abstract Book of the Sport Science Conference AESA 2017 (2), Amol: Faculty of Sport Sciences, Shomal University; Asian Exercise and Sport Science Association.

Popovic, S., Bjelica, D., Georgiev, G., Krivokapic, D., \& Milasinovic, R. (2016) Body Height and its Estimation Utilizing Arm Span Measurements in Macedonian Adults. Anthropologist, 24(3), 737-745.

Popovic, S., Bjelica, D., Molnar, S., Jaksic, D., \& Akpinar, S. (2013). Body Height and Its Estimation Utilizing Arm Span Measurements in Serbian Adults. International Journal of Morphology, 31(1), 271-279.

Popovic, S., Bjelica, D., Tanase, G.D., \& Milasinovic, R. (2015). Body Height and Its Estimation Utilizing Arm Span Measurements in Bosnian and Herzegovinian Adolescents. Montenegrin Journal of Sports Science and Medicine, 4(1), 29-36.

Quanjer, P.H., Capderou, A., Mazocioglu, M.M., Aggarwal, A., Popovic, S Datta Banik, S., Tayie, F.A.K., Golshan, M., Ip, M.S.M., \& Zelter, M. (2014). All-age relationship between arm span and height in different ethnic groups. European Respiratory Journal, 44(4), 905-912.

Reeves, S.L., Varakamin, C., \& Henry, C.J. (1996). The relationship between arm-span measurements and height with special reference to gender and ethnicity. European Journal of Clinical Nutrition, 50(6), 398-400.

Singh, A., Kumar, A., Chavali, K.H., \& Harish, D. (2012). Use of arm-span and foot length for estimation of height of the person. Journal of Punjab academy of forensic medicine and toxicology, 12(2), 87-91.

Szollosi, E. (1998). Secular trend in Debrecen university students (in Hungerian). Anthropologiai Kozlemények, 39, 43-51.

Steele, M.F. \& Chenier, T.C. (1990). Arm-span, height and age in black and white women. Annals of Human Biology, 17(6), 533-541.

Ter Goon, D., Toriola, A.T., Musa, D.I., \& Akusu, S. (2011). The relationship between arm span and stature in Nigerian adults. Kinesiology, 43(1), 38-43.

Wronka, I. \& Pawlinska-Chmara, R. (2009). Childhood environment and adult height among Polish university students. Collegium Antropologicum, 33(4), 1039-1045.

Grasgruber, P. (2016). Personal communication. Masaryk University, Brno, Czech Republic, Czech Republic.

Jurak, G. (2017). Personal communication. University of Ljubljana, Ljubljana, Slovenia, Slovenia. 